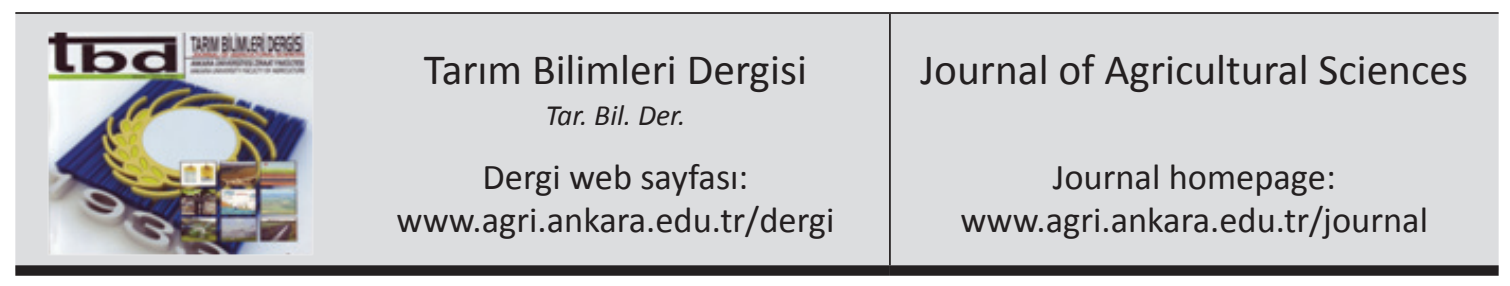

\title{
Kuru İncir Zararlısı Carpophilus hemipterus (L.) (Coleoptera: Nitidulidae)'un Değişik Yaşı Pupalarına Fosfin Gazının Etkisi
}

\author{
Şule TÜTÜNCÜa, Mevlüt EMEKCİ ${ }^{b}$ \\ ${ }^{a}$ Ankara Üniversitesi, Kalecik Meslek Yüksekokulu, Ankara, TÜRKIYE \\ ${ }^{b}$ Ankara Üniversitesi, Ziraat Fakültesi, Bitki Koruma Bölümü, Ankara, TÜRKIYYE
}

\section{ESER BİLGISİ}

Araştırma Makalesi

DOI: 10.1501/Tarimbil_0000001298

Sorumlu Yazar: Şule TÜTÜNCÜ, E-posta: suletutuncu@hotmail.com, Tel: +90 (312) 8571394

Geliş Tarihi: 31 Ocak 2014, Düzeltmelerin Gelişi: 18 Mart 2014, Kabul: 22 Mart 2014

\begin{abstract}
ÖZET
Bu çalışmada Türkiye'nin kuru incir sektöründe metil bromit alternatifi olarak fosfin gazının etkinliği laboratuvar koşullarında araştırılmıştır. $\mathrm{Bu}$ amaçla $15,20,25{ }^{\circ} \mathrm{C}$ sıcaklık ve \% 75 orantılı nem koşullarında Carpophilus hemipterus'un 0-24, 24-48 ve 48-72 saat yaşlı pupalarına 2-24 saat arasında değişen sürelerde 200 ppm fosfin gazı uygulanmıştır. Uygulama $500 \mathrm{~mL}$ hacimli gaz yıkama şişelerinde gerçekleştirilmiştir. Araştırma sonunda elde edilen veriler probit analizine tabi tutularak $\mathrm{LT}_{50}$ değerleri hesaplanmıştır. En yüksek $\mathrm{LT}_{50}$ değeri yaklaşık 12 saat olarak $15^{\circ} \mathrm{C}$ sıcaklıkta 0-24 saat yaşlı pupada tespit edilmiştir. Araştırma sonucunda her 3 sıcaklıkta 0-24 saat yaşlı pupanın diğer pupalara göre daha dayanıklı olduğu tespit edilmiştir. Sıcaklık artışı mutlak ölüm için gereken süreyi kısaltmıştır. Elde edilen sonuçlar fosfin gazının kuru incir sektöründe etkili olarak kullanımına ilişkin uygulama rehberi geliştirilmesine yönelik önemli bilgiler içermektedir.
\end{abstract}

Anahtar Kelimeler: Ekşilik böceği; Fosfin; Pupa; LT değerleri; Uygulama süresi

\section{The Effect of Phosphine Gas to Pupae of Different Ages of The Dried Fruit Beetle, Carpophilus hemipterus (L.) (Coleoptera: Nitidulidae)}

\section{ARTICLE INFO}

Research Article

Corresponding Author: Şule TÜTÜNCÜ, E-mail: suletutuncu@hotmail.com, Tel: +90 (312) 8571394

Received: 31 January 2013, Received in Revised Form: 18 March 2014, Accepted: 22 March 2014

\section{ABSTRACT}

The efficacy of phosphine gas as an alternative to methyl bromide for the dried fig production in Turkey was evaluated under laboratory conditions. For this purpose, 0-24, 24-48 and 48-72 h old pupae of Carpophilus hemipterus were exposed to $200 \mathrm{ppm}$ phosphine at $15,20,25{ }^{\circ} \mathrm{C}$ and $75 \% \mathrm{r}$.h. for $2-24 \mathrm{~h}$ of exposure periods. Phosphine treatments were performed in gas washing bottles of $500 \mathrm{~mL}$-volume. The mortality rates for different exposure periods were subjected to probit analysis, and $\mathrm{LT}_{50}$ values were calculated. The highest $\mathrm{LT}_{50}$ value was recorded as to be 12 hours on $0-24 \mathrm{~h}$-old 
pupae at $15^{\circ} \mathrm{C}$. In this research, 0-24 -hours-old pupae were the most tolerant than the others at all temperatures. Increase in temperature shortens the time needed for complete mortality. These results are of importance for developing effective treatment schedules for disinfestation of dried figs on a commercial scale.

Keywords: Dried fruit beetle; Phosphine; Pupae; LT values; Exposure periods

(C) Ankara Üniversitesi Ziraat Fakültesi

\section{Giriş}

Ülkemizde yaş ve kuru incirlerin önemli bir zararlısı olan Carpophilus hemipterus incir dışında birçok kurutulmuş meyvede zarar yapabilmektedir. Türkiye, dünya kuru incir üretiminin \% 53'ünü ve dünya ihracatının \% 63'ünü karşılaması ile dünya incir sektöründe ilk sırada yer almaktadır (IBPP 2014). 2014 y1lı verilerine göre 2012-2013 sezonu Türkiye kuru incir ihracat1 60.700 ton olarak gerçekleşmiş ve karşılığında 190 milyon ABD Doları döviz girdisi sağlanmıştır (EİB 2014). Böylesine önemli girdisi olan ürünlerde bulaşmalardan kaynaklanan geri dönüşleri ortadan kaldırmak için etkili mücadele stratejileri geliştirmek önemlidir. $\mathrm{Bu}$ bağlamda ülkemizde uygulanan ve üzerinde çalışılan alternatif mücadele yöntemleri arasında yüksek $\mathrm{CO}_{2}$, yüksek basınç $+\mathrm{CO}_{2}$, düşük sıcaklıklarda depolama, şoklama (düşük sıcaklık uygulaması) ve fosfin kullanımı sayılabilir (Emekci \& Ferizli 2000). Depolanmış ürünlerde böcek bulaşmalarını hızlı bir şekilde ortadan kaldırmada en etkili yöntemlerden biri fümigasyondur. Sizdırmazlığın sağlandığ1 varsayılan ortamlarda dahi fümigasyon uygulamalarının başarısı doz, uygulama süresi, sicaklık, orantılı nem, biyolojik evre ve yaşı gibi diğer bir dizi faktöre bağlı olmaktadır. Böceklerin fümigantlara karşı tepkileri böcek türü ve biyolojik evrelerine bağlı olarak önemli değişiklikler göstermekte ve bu durum doz tavsiyelerini çok karmaşık hale getirmektedir. Kurutulmuş incir fümigasyonunda amaç en düşük dozda ve en kısa fümigasyon süresinde mutlak ölüme ulaşmaktır. Bu amaca en uygun fümigant olarak ülkemizde Montreal Protokolü uyarınca 2007 yılında yasaklanıncaya kadar metil bromit kullanılmakta idi (Ferizli \& Emekci 2010). 1930'lardan günümüze kadar tüm dünyada çok değişik ürün gruplarında yaygın olarak kullanılan fumigantlardan biri olan fosfin, metil bromitin yasaklanmasının ardından alternatif bir fümigant olarak kuru incirlerde ülkemizde de kullanılmaya başlamıştır (Ferizli \& Emekci 2010). Fosfin kullanımı kolay, ucuz, kalıntısı az olan ve yaygın olarak benimsenmiş bir fümiganttır (Collins et al 2005). Kuru incir zararlılarının fosfin gazına karş1 gösterdikleri letal tepkilerin zararlıların türü, biyolojik evresi ve yaşı ile ortam sıcaklığı ve uygulama süresi bakımından ayrıntılı olarak aydınlatılması önemlidir. Dolayısıyla bu araştırmada kuru incirin ülkemizdeki en önemli zararlılarından biri olan $C$. hemipterus'un nispeten dayanıklı olarak bilinen evrelerinden olan pupa evresinin 200 ppm gibi düşük fosfin konsantrasyonuna farklı sıcaklıklardaki tepkisi değişik pupa yaşlarında araştırılarak kuru incir sektörüne fosfin gazının kullanımında rehberlik edilmesi amaçlanmıştır.

\section{Materyal ve Yöntem}

\subsection{Carpophilus hemipterus kültürü}

Carpophilus hemipterus stok kültürü İsrail'den getirtilmiş ve $25 \pm 5^{\circ} \mathrm{C}$ sicaklık ve $\% 75 \pm 5$ orant 1 lı nem koşullarında yapay besin üzerinde yetiştirilmiştir (Donahaye \& Navarro 1989). Araştırma 2005-2006 yıllarında laboratuvar çalışması olarak Ankara ilinde yürütülmüştür.

\subsection{Biyolojik evreler}

Değişik yaşlı pupaları elde etmek için yaklaşık 100 adet 1-2 hafta yaşlı karışı cinsiyette ergin içinde yaklaşık 20-25 gram yapay besin bulunan 1 L'lik cam kavanoza aktarılmıştır. Ergin aktarılan bu kavanozlardan 24 saat sonra kavanoz ağzına gerilen Amerikan bezi dikkatlice alınmış ve bezin gözenekleri arasına birakılan 0-24 saatlik yumurtalar dikkatlice petri kabına aktarılmıştır. Bu şekilde elde edilen 0-24 saatlik yumurtalarla açılan 
böcek kültürleri 10. günden itibaren her gün aynı saatte olacak şekilde dikkatlice kontrol edilmiş ve oluşan pupalar günlük olarak kültürlerden toplanmıştır. Toplanan 0-24 saatlik pupalar iklimlendirme odasında 24 ve 48 saat bekletilmek suretiyle sirasiyla $24-48$ ve $48-72$ saatlik pupalar elde edilmiştir.

\subsection{Gaz üreteci ve deneme düzeneği}

Çalışmalarda kullanılan gaz halindeki fosfin $\left(\mathrm{PH}_{3}\right)$ gaz üretecinde Phosphone ${ }^{\circledR}$ tabletlerinden (\% 57 $\mathrm{AlPH}_{3}$ ) üretilmiştir. Alüminyum fosfit tabletinden küçük bir parça (yaklaşı $0.5 \mathrm{~g}$ ) içinde $\% 5$ oranda $\mathrm{H}_{2} \mathrm{SO}_{4}$ içeren $200 \mathrm{~mL}$ 'lik gaz büretine atılmıştır (FAO 1975). Gaz büretinin üst kısmında toplanan $\mathrm{PH}_{3}$ gazı bürete bağlı septumdan (Mininert Valf kilidi açılarak) 10 mL' lik özel gaz şırıngası ile girilerek alınmıştır. Deneme için seri olarak birbirine bağlı $500 \mathrm{~mL}$ hacimli gaz yıkama şişelerinden oluşan bir düzenek kurulmuştur. $\mathrm{Bu}$ düzeneğe elektrokimyasal detektör $\left(\mathrm{PH}_{3}\right.$ spesifik) (Bedfont) ve gazın dağıtımını sağlamak için bir sirkülasyon pompası bağlanmıştır. Deneme öncesi gaz yıkama şişelerine \% 75 orantılı nemi sağlayacak şekilde $10 \mathrm{~mL}$ 'lik PVC kaplarda $5 \mathrm{~mL}$ KOH çözeltisi (Solomon 1951) ilave edilmiştir. Hazırlanan gaz yıkama şişelerine deneme kapları yerleştirildikten sonra düzenekteki tüm gaz yolları açılarak gaz sirkülasyon pompası çalıştırılmıştır. Fosfin gazı özel bir şırınga (gaz geçirmez-kilit valfli) yardımıyla düzeneğin bağlantı borusuna daha önceden yerleştirilmiş olan sabit valfli şırınga iğnesinden girilerek verilmiştir. Düzenekte gereken gaz konsantrasyonuna (200 ppm) ulaşılması ve bu konsantrasyonun sabit hale gelmesi yaklaşık 15 dakika almıştır. Denemelerde uygulama süresi bu işlemin ardından değerlendirmeye alınmıştır.

\subsection{Uygulama}

Gaz düzeneğinde yer alan gaz yıkama şişelerine deneme için hazırlanan $0-24,24-48$ ve $48-72$ saatlik pupaları içeren $25 \mathrm{~mL}$ hacimli PVC kaplar yerleştirilerek gaz verme işlemi başlatılmıştır. PVC kapların kapaklarına açılan $1 \mathrm{~cm}$ çapındaki deliklere hava giriş çıkışına imkân vermek bakımından 250 mesh elek teli yapıştırılmıştır. İstenilen gaz konsantrasyonuna ulaşılmasının ardından sirkülasyon pompası kapatılmış, tüm gaz akış vanaları kapatılarak gaz yıkama şişeleri düzenekten ayrılmış ve 15,20 veya $25{ }^{\circ} \mathrm{C}$ sicaklıklara ayarlı Unitest marka iklim dolabına yerleştirilmiştir. Uygulama süresi sonunda iklim dolabından çıkarılan gaz yıkama şişeleri açılarak havalandırılmış ve $25{ }^{\circ} \mathrm{C}$ sıcaklık $\% 75 \pm 5$ orantılı nemdeki iklimlendirme odasında \% 75 orant11 nem veren $\mathrm{KOH}$ çözeltisi bulunan desikatörlerde ölümler belirleninceye kadar tutulmuştur. Kontrol amaciyla hazırlanan pupa kapları fosfin uygulamalarındakine benzer bir düzenekte aynı sıcaklık değerleri ve uygulama sürelerinde sadece normal hava sirkülasyonuna tabi tutulmuştur. $\mathrm{Bu}$ süre sonunda kontrol grubunu içeren PVC kaplar iklimlendirme odasında \% 75 nem ihtiva eden desikatörlere yerleştirilmiştir. Deneme boyunca inkübatör sıcaklığı ve deneme sonrası desikatör nem ve sicaklığ 1 Hobo ${ }^{\circledR}$ ProTemp/RH marka veri kaydedici ile ölçülmüş ve kaydedilmiştir. Denemeler en az 3'er tekerrürlü olarak kurulmuş ve her tekerrürde 30'ar adet pupa kullanılmıştır. Uygulama süresi 2 saatle başlayıp 2'şer saat artırılarak devam etmiş ve 24 saatle -tespit edilen en uzun mutlak ölüm süresi- sonlandırılmıştır.

\subsection{Uygulama sonrası gözlemler}

Sonuçların değerlendirilmesinde gözlemler pupa yaş1 ve uygulama süresine göre değişmekle birlikte fümigasyonu takip eden 9. günden itibaren başlamış ve yapılan günlük kontrollerle ergin olanlar yumuşak pens yardımıyla sayıları kaydedilerek deneme kabından uzaklaştırılmıştır. Gözlemler, pupalar ölüp kararıncaya veya ergin oluncaya kadar devam etmiştir. Ergin olanların sayısına göre canlı ve ölü sayıları belirlenmiştir.

\subsection{Istatistiksel analiz}

Toplam ve canlı birey sayıları kullanılarak POLO PC programina göre probit analizi yapılarak $\mathrm{LT}_{50}$ değerleri belirlenmiş (LeOra Software); sonuçların kıyaslanmasında letal-doz oranı testi kullanılmıştır (Robertson et al 2007). 


\section{Bulgular ve Tartışma}

Değişik yaşlı pupaların probit sonuçlarını içeren değerler Çizelge 1 ve 2 'de verilmiştir. Ölümler sıcaklık-yaş artışıyla doğru orantılı olarak artmış ve 24 saatlik uygulama değişik yaşlı tüm pupaların ölümü için yeterli olmuştur (Şekil 1-3). Çizelge 1 ve 2'ye dikkat edilecek olursa sıcaklık artışılla ölüm için gereken sürenin kısaldığı azalan LT değerleriyle görülmektedir. Genç pupaların yaşlı pupalara kıyasla fosfine karşı daha dayanıklı olduğu artan eğim değerleriyle görülmektedir (Çizelge 1). LT değerlerindeki en fazla değişim 15 ve $25^{\circ} \mathrm{C}$ sıcaklıklar arasında görülmektedir. Sonuçlar kıyaslanırken LT değerlerine ait 0.95 güven aralığı değerlerinin çakışmasına göre yapılan değerlendirmede istatistiksel olarak bazı sakıncalar tespit edilmiş olduğundan (Robertson et al 2007) bu araştırmada 3 sıcaklık ve 3 yaş grubuna ait veriler letal doz oranı testiyle değerlendirilmiştir. Letal doz oranı testine göre pupa yaşları arasındaki fark $15{ }^{\circ} \mathrm{C}$ sıcaklıkta önemli iken sıcaklık artışı bu farkı ortadan kaldırmış 20 ve $25{ }^{\circ} \mathrm{C}$ sıcaklıklarda 2 ve 3 gün yaşlı pupalar arasındaki fark önemli bulunmamıştır (Çizelge 2).

Carpophilus hemipterus'un pupa evresi üzerinde düşük fosfin konsantrasyonlarının öldürücü etkisi ile ilgili olarak literatürde yeterli sayıda çalışma bulunmadığından araştırma bulgularını kıyaslamakta zorluk yaşamaktayız. Dolayısıyla kurutulmuş meyve zararlıları başta olmak üzere diğer depolanmış ürün zararlıları ile yapılan benzer araştırma sonuçlarını kıyaslamak mümkün olabilmektedir. Düşük doz fosfin uygulamalarında ölümün fosfin konsantrasyonu veya uygulama süresinden çok sıcaklığa bağlı olduğu, yüksek sıcaklıkların fosfinin etkinliğini artırdığını

Çizelge 1- Üç farklı sıcaklıkta 200 ppm fosfin uygulaması sonucu Carpophilus hemipterus'un değişik yaşlı pupalarında tespit edilen eğim değerleri ve denek sayıları

Table 1-Sample sizes and slopes determined following a 200 ppm phospine application to pupae of various ages of Carpophilus hemipterus at three temperatures

\begin{tabular}{ccccccc}
\hline \multicolumn{7}{c}{ Sicaklik $\left({ }^{\circ} \mathrm{C}\right)$} \\
\hline \multirow{2}{*}{ Yaş (saat) } & $n$ & Ĕğim (SH) & $n$ & Eğim (SH) & $n$ & Ĕğim (SH) \\
\cline { 2 - 7 } $0-24$ & 517 & $11.065(1.139)$ & 531 & $11.742(1.822)$ & 431 & $6.087(0.568)$ \\
$24-48$ & 446 & $14.644(1.399)$ & 362 & $14.804(2.068)$ & 363 & $13.995(1.651)$ \\
$48-72$ & 359 & $18.488(1.759)$ & 360 & $14.050(1.647)$ & 365 & $16.427(2.293)$ \\
\hline
\end{tabular}

Çizelge 2- Üç farklı sıcaklıkta 200 ppm fosfin uygulaması sonucu Carpophilus hemipterus'un değişik yaşlı pupalarında tespit edilen $\mathbf{L T}_{50}$ (güven aralığı \% 95) değerleri (saat)

Table 2- $L T_{50}$ values (with $95 \% \mathrm{Cl}$ ) determined following a 200 ppm phospine application to pupae of various ages of Carpophilus hemipterus at three temperatures (hours)

\begin{tabular}{cccc}
\hline \multicolumn{4}{c}{ Sicaklik $\left({ }^{\circ} \mathrm{C}\right)$} \\
\hline Yaș (saat) & 15 & 20 & 25 \\
\hline \multirow{2}{*}{$0-24$} & $12.462 \mathrm{Aa}$ & $8.938 \mathrm{Ab}$ & $5.337 \mathrm{Ac}$ \\
& $(11.666-13.098)$ & $(7.735-9.666)$ & $(4.499-6.010)$ \\
$24-48$ & $10.519 \mathrm{Ba}$ & $6.451 \mathrm{Bb}$ & $4.440 \mathrm{Bc}$ \\
& $(10.152-10.848)$ & $(5.376-7.089)$ & $(4.255-4.634)$ \\
$48-72$ & $9.292 \mathrm{Ca}$ & $6.082 \mathrm{Bb}$ & $4.358 \mathrm{Bc}$ \\
& $(8.813-9.723)$ & $(5.823-6.313)$ & $(4.201-4.546)$ \\
\hline
\end{tabular}

a, her sütun içerisinde farklı büyük harfler ve satır içerisinde farklı küçük harfler önemli derecede farklıdır (letal-doz oranı testi P $<0.05$ "1" değerini içermiyorsa önemlidir) 


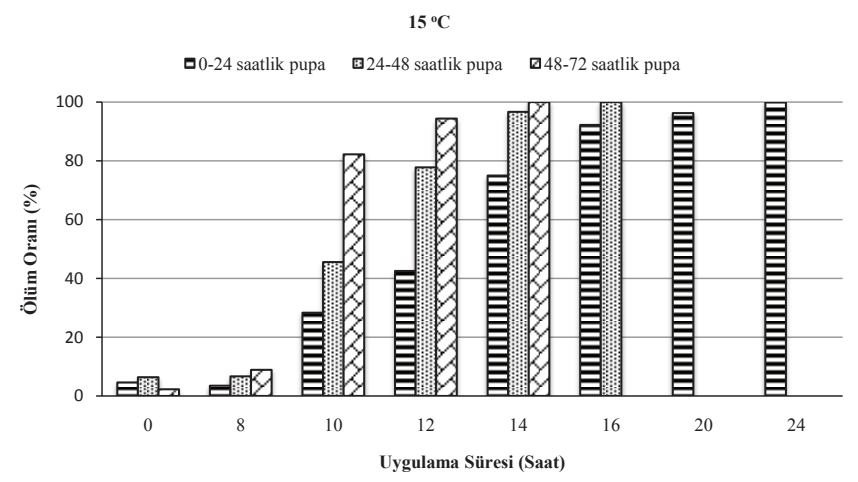

Şekil 1- Değişik sürelerde uygulanan 200 ppm fosfin gazının, $15^{\circ} \mathrm{C}$ sıcaklıkta, Carpophilus hemipterus'un pupaları üzerindeki letal etkileri

Figure 1-Lethal effects of 200 ppm phosphine on the pupae of Carpophilus hemipterus for various exposure times at $15^{\circ} \mathrm{C}$

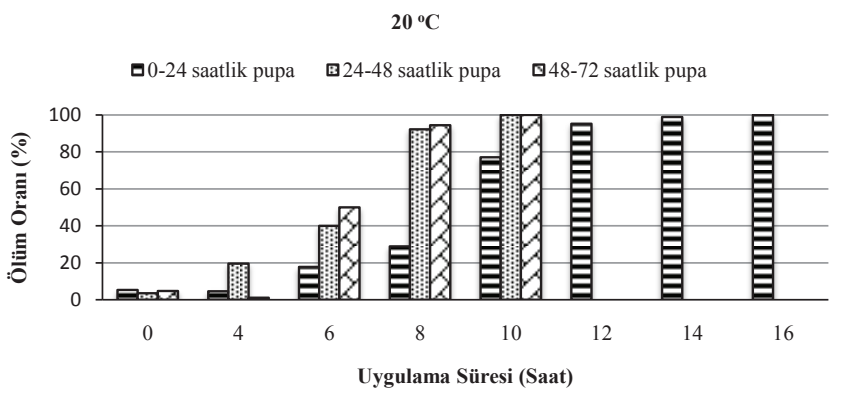

Şekil 2- Değişik sürelerde uygulanan 200 ppm fosfin gazının, $20{ }^{\circ} \mathrm{C}$ sıcaklıkta, Carpophilus hemipterus'un pupaları üzerindeki letal etkileri

Figure 2-Lethal effects of 200 ppm phosphine on the pupae of Carpophilus hemipterus for various exposure times at $20^{\circ} \mathrm{C}$

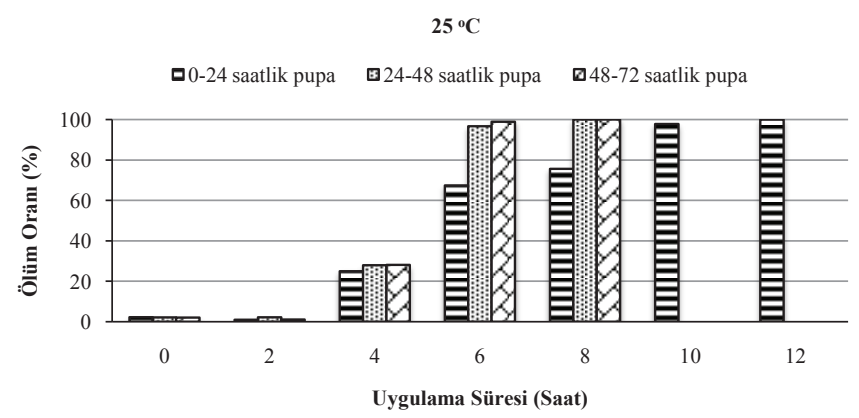

Şekil 3- Değişik sürelerde uygulanan 200 ppm fosfin gazının, $25^{\circ} \mathrm{C}$ sıcaklıkta, Carpophilus hemipterus'un pupaları üzerindeki letal etkileri

Figure 3-Lethal effects of 200 ppm phosphine on the pupae of Carpophilus hemipterus for various exposure times at $25^{\circ} \mathrm{C}$ 
önceki çalı̧̧malarda görmekteyiz. Sitophilus oryzae, Tribolium castaneum, Plodia interpunctella ve Rhizoperta dominica'nın değişik evreleri ile yapılan bir araştırmada $32{ }^{\circ} \mathrm{C}$ sicaklıkta $S$. oryzae pupalarında 48 saatlik uygulama ile \% 100 ölüme ulaşılırken sıcaklık $18{ }^{\circ} \mathrm{C}$ 'ye düştüğünde mutlak ölüme ulaşılamamıştır. Aynı araştırmada $R$. dominica pupalarında mutlak ölüm $32{ }^{\circ} \mathrm{C}$ sıcaklıkta 18 saatte gerçekleşirken sıcaklık $18{ }^{\circ} \mathrm{C}$ 'ye indiğinde mutlak ölüm süresi 48 saate uzamıştır (Phillips et al 1998).

Lasioderme serricorne' nin dayanıklı ve hassas ırkının ergin ve larvalarına $200 \mathrm{ppm}$ dozunda fosfinin 5 farklı sicaklık derecesinde uygulandığı benzer bir çalışmada, her iki rrktada sıcaklık $25^{\circ} \mathrm{C}$ 'den 5 ${ }^{\circ} \mathrm{C}$ düşürülünce fosfin alımı azalmış ve dolayısıyla düşük sıcaklıklarda ölüm oranları da düşük olmuştur. Hassas irkın larvalarında 5 ve $25{ }^{\circ} \mathrm{C}$ sicaklıklarda tespit edilen ölüm oranları sirasiyla \% 61.11 ve $\%$ 98.48'dir (Chaudhry et al 2004). Sıcaklık artışıla ölüm süresinin kısalmasına ilişkin olarak Flinn et al (2000) Rhizoperta dominica' nın tüm biyolojik evrelerine $10-35{ }^{\circ} \mathrm{C}$ sicakliklarda $180 \mathrm{ppm}(0.25$ $\mathrm{g} \mathrm{L}^{-1}$ ) dozunda fosfin uygulamış; pupalarda 15 , 20 ve $25{ }^{\circ} \mathrm{C}$ sicaklıklardaki $\mathrm{LT}_{95}$ değerini sırasıyla $1.7,0.9$ ve 0.5 gün olarak tespit etmiştir. Alpay (2006)'ın C. hemipterus' un değişik dönemleriyle 20 ve $25^{\circ} \mathrm{C}$ sıcaklıklarda yaptığı araştırmada $0-24$ saat yaşlı yumurtalarda tespit edilen $\mathrm{LT}_{50}$ değerinin $20{ }^{\circ} \mathrm{C}$ sicaklıkta yaklaşık 18 saatten $25^{\circ} \mathrm{C}$ sicaklıkta 16 saate düştüğü tespit edilmiştir. Araştırmacı, erginlerde $20^{\circ} \mathrm{C}$ sıcaklıkta 5 saat olan mutlak ölüm süresinin sıcaklığın $25^{\circ} \mathrm{C}$ 'ye yükselmesiyle 4 saate indiğini tespit etmiştir. Çalışmamızdaki sonuçları destekleyen bir diğer veri Nayak \& Collins (2008) tarafından Liposcelis bostrychophila'nın tüm biyolojik dönemleri ile yapılan çalışmada ortaya konmuştur. Araştırmacılar yüksek sıcaklığın fumigasyon periyodunu kısalttığını; 0.1 ve $1.0 \mathrm{mg} \mathrm{L}^{-1}$ fosfin uygulamasında mutlak ölümün $15^{\circ} \mathrm{C}$ sıcaklıkta sirasiyla 9 ve 11 günde; $35^{\circ} \mathrm{C}$ sicaklıkta ise sirasiyla 2 ve 4 günde sağlandığını bildirmektedir.

Biyolojik dönemin yaşı da fümigasyon başarısında önemli rol oynamaktadır. Pupa yaşı artışıyla fosfine dayanıklılığın azaldığı dair bulgular Howe (1973), Akan (2003) ve Alpay (2006) tarafindan ifade edilmektedir. $25{ }^{\circ} \mathrm{C}$ sicaklık ve $\% 70$ orantılı nem koşullarında Sitophilus granarius'un tüm biyolojik evreleri ile $1 \mathrm{mg} \mathrm{L}^{-1}$ (718 ppm) fosfin dozunda 32 saat süreli olarak yapılan bir araştırmada yaş ilerledikçe hassasiyetin arttığ 1 tespit edilmiştir. Araştırmada 1 ve 2 günlük pupalar 5 günde ölürken 5 ve 6 günlük pupalar ise sirasıyla 3 ve 4 günde ölmüştür (Howe 1973). Oryzaephilus surinamemsis'e $200 \mathrm{ppm}$ fosfin gazının $30{ }^{\circ} \mathrm{C}$ sıcaklıkta uygulandığı bir diğer araştırmada, 2 saatlik uygulama sonunda 1 ve 2 günlük pupalarda ölüm oranı $\% 44$ olarak tespit edilirken 2 günlük pupalardaki ölüm oranı \% 46 olarak saptanmıştır. Her iki yaş grubundaki pupalarda mutlak ölüm 12 saatlik uygulama sonunda elde edilmiştir (Akan 2003). C. hemipterus' un 1, 2 ve 3 günlük pupalariyla $50 \mathrm{ppm}$ fosfin konsantrasyonunda yapılan çalışmada $\mathrm{LT}_{50}$ değerleri $20{ }^{\circ} \mathrm{C}$ sicaklıkta sirasiyla $12.5,8.8$ ve 10.6 saat olarak tespit edilmiş; sıcaklığın $25{ }^{\circ} \mathrm{C}$ 'ye yükselmesiyle söz konusu değerler pupa yaşı bağlamında çok fazla değişmeyerek sırasıyla 7.5, 7.8 ve 7.7 saat olmuştur (Alpay 2006). $25^{\circ} \mathrm{C}$ sıcaklıkta LT değerlerindeki bu yakınlık çalışmamızda da dikkat çekmektedir; $15^{\circ} \mathrm{C}$ sicaklıkta letal doz oranı sonucuna göre önemli olan yaş fark 20 ve $25^{\circ} \mathrm{C}$ sıcaklıklarda 2 ve 3 gün yaşlı pupalarda önemsiz bulunmuştur (Çizelge 2). Aynı şekilde bu iki sıcaklık derecesinde mutlak ölüm süreleri açısından 2 ve 3 gün yaşlı pupalar arasında fark olmadığı da görülebilmektedir (Şekil 2-3).

Phillips et al (1998) ve Keever et al (1998)'e atfen Keever (2004) ayrıntılı literatür değerlendirmesinde diyapozdaki larva hariç larva ve erginlerin pupa ve yumurtalardan daha kolay öldürüldüğü sonucuna varmıştır. Pupa evresinin nispeten dayanıklı bir evre olduğunu gösteren verileri Flinn et al ile Akan, Alpay ve Kahraman'ın yaptığı çalışmalarda da görebilmekteyiz (Flinn et al 2000; Akan 2003; Alpay 2006; Kahraman 2009). Akan (2003) ve Kahraman (2009)'ın çalışmalarında yumurta> pupa> ergin> larva şeklindeki dayanıklılık sıralaması; Flinn et al (2000) ve Alpay (2006)'ın çalışmalarında yumurta> pupa $>$ larva $>$ ergin olarak tespit edilmiştir. Pupa evresinin dayanıklı evrelerden biri olması sebebiyle farklı sıcaklıklarda elde ettiğimiz mutlak ölüm süreleri $C$. hemipterus ile etkili bir mücadele için yol gösterici niteliktedir. 


\section{Sonuçlar}

Burada sunulan çalışmanın kuru incirlerin işlenme sezonunda karşılaşılabilecek 3 ayrı sıcaklık derecesinde yapılmış olması ile uygulayıcılara geniş bir sıcaklık aralığında ayrıntılı bilgi sağlamak amaçlanmıştır. Araştırmada sıcaklık artışıyla ölüm için gereken sürenin kısaldığı tespit edilmiştir. Nayak \& Collins (2008)'in de bildirdiği gibi düşük sıcaklıklardaki uygulamalarda fosfin gazının etkili olabilmesi için dozu artırmak yerine uygulama süresinin uzun tutulması önemlidir. Elde edilen veriler uygulayıcı konumundaki kişi ve kurumlara etkili bir fosfin fümigasyonu gerçekleştirme yolunda önemli veriler sunmaktadır. Daha da önemlisi bu sonuçlar kurutulmuş incirde fosfinin metil bromitin yerini alabileceğini düşündürmektedir.

\section{Kaynaklar}

Akan K (2003). Fosfin ve fosfin $+\mathrm{CO}_{2}$ uygulamalarının Oryzaephilus surinamensis (L.) (Coleoptera: Silvanidae)'e bazı etkileri üzerinde araştırmalar. Yüksek lisans tezi, Ankara Üniversitesi Fen Bilimleri Enstitüsü (Basılmamış), Ankara

Alpay S (2006). Fosfin gazının Carpophilus hemipterus (L.) (Coleoptera: Nitidulidae)'a farklı sıcaklıklarda etkileri üzerinde araştırmalar. Yüksek lisans tezi, Ankara Üniversitesi Fen Bilimleri Enstitüsü (Basılmamış), Ankara

Chaudhry M Q, Bell H A, Savvidou N \& MacNicoll A D (2004). Effect of low temperatures on the rate of respiration and uptake of phosphine in different life stages of the cigarette beetle, Lasioderma serricorne (F.). Journal of Stored Products Research 40: 125 -134

Collins P J, Daglish G J, Pavic H \& Kopittke R A (2005). Response of mid-age cultures of phosphineresistant and susceptible strains of lesser grain borer, Rhizoperta dominica, to phosphine at a range of concentrations and exposure periods. Journal of Stored Products Resarch 41: 375-385

Donahaye E J \& Navarro S (1989). Sensitivity of two dried fruit pests to methyl bromide alone, and in combination with carbon dioxide or under reduced pressure. Tropical Science 29: 9-14

EİB (2014). Ege İhracatçı Birlikleri http://www.egebirlik. org.tr/asp/ Content. asp? MS= 1\&Id0 (Erişim tarihi: 23.01.2014)

Emekci M \& Ferizli A G (2000). Current status of stored products protection in Turkey. Integrated Protection of Stored Products IOBC Bulletin 23(10): 39-46
FAO (1975). Recommended methods for the detection and measurement of resistance of agricultural pests to pesticides. 16: Tentative method for adults of some major pests of stored cereals with methyl bromide and phosphine. FAO Plant Protection Bulletin 23: 12-25

Ferizli A G \& Emekci M (2010). Depolanmış ürün zararlılarıyla savaşım, sorunlar ve çözüm yolları. TMMOB Ziraat Mühendisleri Odasi Ziraat Mühendisliği VII. Teknik Kongresi, 11-15 Ocak, Ankara, Bildiriler Kitabı 2: 579-587

Flinn P, Phillips T, Hagstrum D, Arthur F \& Throne J (2000). Modeling the effects of insect stage and grain temperature on phosphine-induced mortality for Rhizoperta dominica. In: Proceedings of the International Conference on Controlled Atmospheres and Fumigation in Stored Products, 29 Oct-3 Nov, Fresno, California, pp. 531-539

Howe R W (1973). The susceptibility of the immature and adult stages of Sitophilus granarius to phosphine. Journal of Stored Product Research 8: 241-262

İBP (2014). İhracat Bilgi Platformu http://www.ibp.gov. tr/pg/sektorpdf/tarim/kuru_incir.pdf (Erişim tarihi: 21.01.2014)

Kahraman E (2009). Kuru meyve güvesi, Plodia interpunctella (Hübner) (Lepidoptera: Pyralidae)'ya fosfinin bazı etkileri üzerinde araştırmalar. Yüksek lisans tezi, Ankara Üniversitesi Fen Bilimleri Enstitüsü (Basılmamış), Ankara

Keever D W (2004). Addition of Carbon Dioxide at Low Concentrations to Phosphine: Does It Enhance Phosphine As a Fumigant of Stored- Product Insects? A Review. Degesch America, Inc. Newsletter, Issue VIII

Nayak M K \& Collins P J (2008). Influence of concentration, temperature and humidity on the toxicity of phosphineto the strongly phosphineresistant psocid Liposcelis bostrychophila Badonnel (Psocoptera: Liposcelididae). Pest Management Science 64: 971-976

Phillips T W, Bonjour E L, Payne K, Noyes R T, Cuperus G W, Schmidt C \& Mueller D K (1998). Effects of exposure time, temperature and life stage on mortality of stored grain insects treated with cylinderized phosphine. Proceedings of the $7^{\text {th }}$ International Working Conference on Stored-product Protection, 14-19 October, Beijing, China, pp.320-325

Robertson J L, Russel R M, Preisler H K \& Savin N E (2007). Bioassays with Arthrapods. CRC Press, New York

Solomon M D (1951). Control of humidity with potassium hydroxide, sulphuric acid or other solutions. Bulletin of Entomological Research 42: 543-554 